\title{
Requirements for building information modeling based lean production management systems for construction
}

Article

Accepted Version

Sacks, R., Radosavljevic, M. and Barak, R. (2010)

Requirements for building information modeling based lean production management systems for construction. Automation in Construction, 19 (5). pp. 641-655. ISSN 0926-5805 doi: https://doi.org/10.1016/j.autcon.2010.02.010 Available at https://centaur.reading.ac.uk/8127/

It is advisable to refer to the publisher's version if you intend to cite from the work. See Guidance on citing.

Published version at: http://www.sciencedirect.com/science?_ob=ArticleURL\&_udi=B6V20-4YRPMVH-

$1 \&$ user $=333848 \&$ coverDate $=08 \% 2 \mathrm{~F} 31 \% 2 \mathrm{~F} 2010$ \&_rdoc $=1$ \&_fmt=high\&_orig=search\&_origin=search\&_sort=d\&_doca nchor $=\&$ view $=c \&$ searchStrld $=1499669417 \&$ \&rerunOrigin $=$ scholar.google\&_acct $=C 000017279 \&$

To link to this article DOI: http://dx.doi.org/10.1016/j.autcon.2010.02.010

Publisher: Elsevier Science

All outputs in CentAUR are protected by Intellectual Property Rights law, including copyright law. Copyright and IPR is retained by the creators or other copyright holders. Terms and conditions for use of this material are defined in the End User Agreement. 


\section{CentAUR}

Central Archive at the University of Reading

Reading's research outputs online 


\title{
Requirements for Building Information Modeling based Lean
}

\section{Production Management Systems for Construction}

\author{
Rafael Sacks ${ }^{1}$, Milan Radosavljevic ${ }^{2}$, Ronen Barak ${ }^{3}$
}

\section{Abstract}

Smooth flow of production in construction is hampered by disparity between individual trade teams goals and the goals of stable production flow for the project as a whole. This is exacerbated by the difficulty of visualizing the flow of work in a construction project. While the addresses some of the issues in Building information modeling provides a powerful platform for visualizing work flow in control systems that also enable pull flow and deeper collaboration between teams on and off site. The requirements for implementation of a BIM-enabled pull flow construction management software system based on the Last Planner System ${ }^{\mathrm{TM}}$, called 'KanBIM', have been specified, and a set of functional mock-ups of the proposed system has been implemented and evaluated in a series of three focus group workshops. The requirements cover the areas of maintenance of work flow stability, enabling negotiation and commitment between teams, lean production planning with sophisticated pull flow control, and effective communication and visualization of flow. The evaluation results show that the system holds the potential to improve work flow and reduce waste by providing both process and product visualization at the work face.

\section{Keywords}

Building Information Modeling; Lean construction; Process visualization; Production control; KanBIM

\footnotetext{
${ }^{1}$ Corresponding author: Assoc. Prof., Faculty of Civil and Env. Eng., Technion - Israel Institute of Technology, Haifa, Israel; cvsacks@techunix.technion.ac.il

${ }^{2}$ Lecturer, School of Construction Management and Engineering, University of Reading, Reading, UK; m.radosavljevic@reading.ac.uk

${ }^{3}$ Adjunct Lecturer, Faculty of Civil and Env. Eng., Technion - Israel Institute of Technology, Haifa, Israel; ronen@rbarak.com
} 
Requirements for Building Information Modeling based Lean Production Management Systems for Construction Accepted 2/2010 for Automation in Construction

(C) 2010 Sacks, Radosavljevic, Barak

\section{Introduction}

Construction projects typically involve multiple discrete organizations working simultaneously on congested sites. They suffer from waste that is manifested in waiting time for crews, rework, unnecessary movement and handling of materials, unused inventories of workspaces and of materials, etc. Achieving smooth work flow with minimal waste requires not only appropriate construction planning, but also effective production management.

Lean thinking applied to construction has led to development of planning and control systems and other practices that improve matters. Koskela's 'Transformation-Flow-Value' (TFV) conceptualization of production in construction [1] provides a theoretical basis for appreciating the flow and value aspects of construction in addition to the well established transformation view. Applied research using discrete event simulation has clearly shown the adverse impact of variation in production and delivery rates $[2,3]$ and the benefits of pull flow of trade teams according to information maturity [4].

In practice, the Last Planner System ${ }^{\mathrm{TM}}$ (LPS) [5] and adaptations of it are increasingly applied to reduce variation, improve coordination and work flow, and thus to reduce various forms of waste in construction projects. While a detailed explanation of the LPS is beyond the scope of this paper, we list the principles that underpin it as they are the foundation for much of what follows. Koskela [6] outlined five principles for a production control system:

- assignments should be sound regarding their prerequisites (i.e. constraints must be released)

- the realization of assignments is measured and monitored (in LPS the percent plan complete measure serves this purpose)

- causes for non-realization are investigated and those causes are removed

- a buffer of unassigned tasks which are sound for each crew is maintained 
- in look ahead planning, the prerequisites of upcoming assignments are actively made ready

In his definitive work on the LPS [5], Ballard added the following:

- Variability must be mitigated and remaining variability managed

- The traditional schedule-push system is supplemented with pull techniques

- Production control facilitates work flow and value generation

- The project is conceived as a temporary production system

- Decision making is distributed in production control systems

- Production control resists the tendency toward local sub-optimization

The LPS was designed to be applied with minimal, if any, information technology support.

Nevertheless, effective production management in construction projects with large numbers of essentially independent work teams and extensive distinct spaces (such as office towers, shopping malls, etc.) remains difficult to achieve. A number of factors make coordination between the trade contractor teams, material and equipment suppliers, construction management personnel, and designers and inspectors difficult. Among them:

- physical dispersion of the teams within the building or across the site, where they are usually hidden from one another by the structure itself;

- contracting relationships with remuneration terms that encourage local optimization and work against overall project optimization [7];

- complex variations in productivity rates [8], which makes it very difficult to predict short term progress;

- lack of effective real-time reporting of progress, despite multiple research efforts aimed at automating this aspect of project control [9]; 
- dependence on key individuals to obtain and communicate critical information regarding constraint status to the look ahead and last planner functions;

- reliance on paper documents to communicate product information, with the limitations of design documentation errors, lack of clarity and potential obsolescence of information [10];

While the LPS reduces variation by improving the reliability of short-term planning, it does not achieve pull flow in the pure sense in that it does not prioritize tasks in relation to signals from downstream demand. In lean production in manufacturing settings, pull flow is implemented using 'Kanban' systems [11]. In manufacturing plants, process visualizations are used to provide flow signals to workers and to empower them to adjust flow to suit the overall system pace [12]. On construction sites, where work teams, not products, move, it is very difficult to visualize the flow of the work in progress and to communicate its status to the teams and individuals involved. The amount of buffered work-in-progress (WIP) accumulated between work teams cannot be seen by the naked eye in the same way that piles of products that constitute WIP can be seen accumulating between processing stations in a manufacturing plant [13].

Another problem is that the most common cycle time used with the LPS is one week (called 'weekly work planning'). The weekly response time is too long to avoid waste in the case of tasks whose constraints are only resolved within days prior to their execution. For example, the maturity of building finishing works that have short task durations and multiple and varying dependencies on information, preceding tasks and equipment, cannot be guaranteed in advance of a one-week window. Where the LPS is used with a shorter planning window (e.g. [14]), it has been done on projects where work is narrowly focused and all participants can easily see the process status, unlike the case of finishing works in large buildings.

Finally, as implemented in practice, the weekly work plans do not make any a priori provision for structured experimentation that could facilitate continuous improvements; rather, the percent-plan complete measure is compiled, which enables retrospective learning from failure, but not planned 
learning from success. Although the formulators of the LPS envisioned that it would support learning from success, the pressures of day-to-day construction make recording of success for learning (both within and beyond the current project) impractical. A computerized system with automated recording and reporting might obviate this difficulty.

To address these issues, we propose that production management systems for construction should be based on BIM platforms and introduce Kanban style pull process flow and Andon alerts. We call this concept 'KanBIM'. We hypothesize that a software system that supplements the LPS by providing ubiquitous access to 3D visualizations of process status and future direction, delivered to all on site and enabling real-time feedback of process status, including Kanban card type pull flow control signals and Andon alerts, can empower people to manage the day to day flow of construction operations with greater reliability and less variability than can be achieved without such a system. The following sections of this paper outline the state of the art, describe the goals and method of a research program underway to develop the KanBIM concept, and establish the requirements for the modes of operation of future KanBIM type software systems.

\section{State of the Art in Software Systems for Production Management in}

\section{Construction}

With few notable exceptions, most of the academic and industrial research on computer-aided design and visualization in construction deals with building design and with pre-construction planning. There has been far less effort to develop Building Information Modeling (BIM) based tools to support coherent production management on site.

The 4D CAD concept [15] has been implemented commercially in dedicated construction planning software (such as CommonPoint [16] and Synchro [17]) and has also been incorporated in fullyfledged BIM tools. Akinci et al. [18] demonstrated how work spaces and temporary facilities could be generated and added to 3D building design models to enable evaluation of construction plans for 
space conflicts. Some systems incorporate cost as a 'fifth dimension' of project information and aim to enable 'virtual construction' [19]. These are appropriate for pre-construction planning and monitoring schedules, but not for day to day production management, because they do not support fine-grained collaborative task negotiation and planning between teams, their displays are not intended for work crews on site, they do not support pull flow control, they do not support explicit checking and removal of constraints, and they do not define activities with sufficient degrees of detail.

Songer et al. (2000) proposed to integrate workflow modeling with 3D CAD to enable visualization of project performance. Two examples of software that implement lean construction flow control, but do not use building models to support visualization, are Choo et al.'s [20] 'WorkPlan' system, which applied a database of work packages and constraints to support the Last Planner System process, and SPS, a commercial package that helps reduce supply chain variations [21].

The Lean Enterprise Web-based Information System (LEWIS) proposed by Sriprasert and Dawood [22] is a sophisticated integration of a building model, a decision support system that performs optimization of construction plans using an evolutionary algorithm, and 4D visualization delivered on a web-based and mobile information management system. It is rooted in the LPS approach in so far as it aims to enable generation of reliable plans and constraint-free execution assignments. The implementation included graphical depiction of constraints, such as material deliveries, by colorcoding objects in a building model view. ConstructSim [23] is a commercial software package which offers model-based work planning (including detailing master plan level activities into detailed 'work packs' for fine-grained production planning), constraint checking by associating building model objects with external supply chain information systems, and visualization of project and work status by color-coding of model objects. Both LEWIS and ConstrucSim fulfill a number of the requirements defined in this paper, but both stop short of direct engagement of the 'last planners' (the trade managers and crew leaders) themselves in operating the system. Their interfaces are designed to be 
operated by engineering management. Neither system provides explicit support for online negotiation of weekly work plans, nor does it support explicit pull flow control. Their process status and forecast visualization are product-centric, in that they make the progression of production visible by displaying the current and future states of the building or plant, but do not explicitly show the locations of work teams or work in progress. TOKMO [24] is a more advanced commercial system, but it too is primarily a desktop solution that does not deal with the dynamics of day to day information delivery and reporting at the workface itself.

An earlier attempt to address these shortcomings, particularly the need to make the project status, not only the product status, visible, used a reporting interface that incorporated symbols akin to traffic signs [25] (see Fig. 1). It was developed to communicate project status to finishing works subcontractors for a shopping mall project, and was based on an earlier experimental interface devised for apartment finishing works. Hewage and Ruwanpura [26] deployed an 'information booth' with a display screen and printer to communicate up-to-date information to workers at the work face, and reported improved levels of productivity due to less time wasted by workers seeking design information. This was restricted to product information and provided only one-way communication.

These few exceptions, in contrast with the rich array of BIM and construction planning software available, reveals neglect of production management on the part of researchers and developers of information technology in construction. This neglect reflects the decline in attention paid to production management on the part of general contractors and construction managers highlighted by Koskela and Howell [27]. For various reasons, construction companies have adopted a hollowedout business model by reducing core staff to a minimum and implementing work through subcontracting [28]. A result of this is the need for fine-grained coordination between work teams that belong to disparate organizations. Kubicki et al. [29] identified the potential to support this need using information technologies. They developed a prototype web interface to communicate 
the status of tasks using text, digital photos, a percent complete measure, information about any problems and providing links to relevant documents. On the basis of a short trial, they then formulated the need for a future broad construction cooperation platform, which would go beyond the 'project dashboard' concept (which is targeted at project managers, [30]) to include direct collaboration between work teams to support their operational decisions ("we think that every actor in the building construction operation should be involved in their task coordination. For example in an inter-actor coordination case, each actor should find relevant indicators related to the activity and should be able to navigate through the project context to better understand the situation" [29].

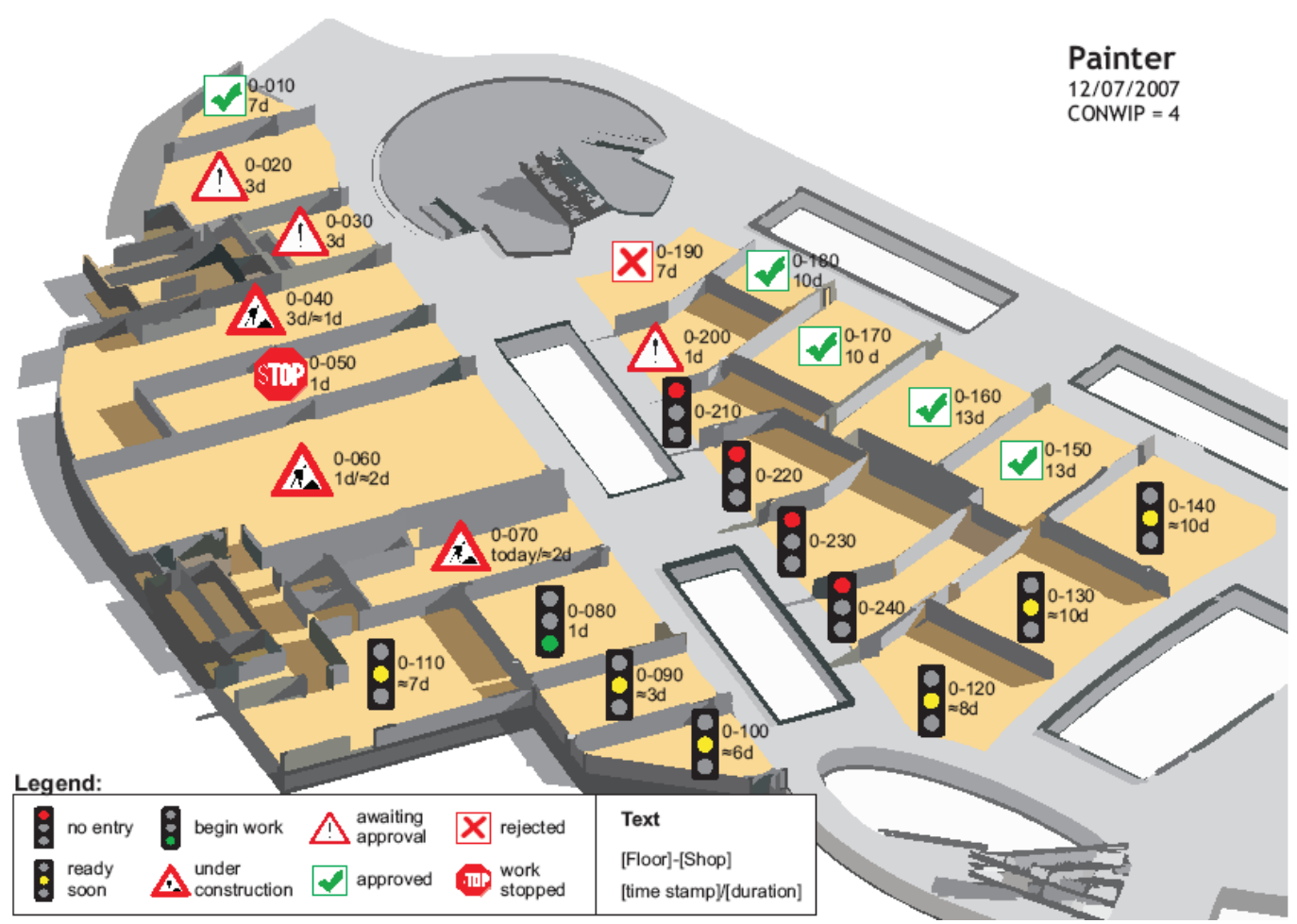

Fig. 1. Proposed 3D visualization of past, present and future work status for a trade [25]. An additional aspect that is not addressed specifically by either the LEWIS research effort or the ConstructSim commercial software is the need to have short-term reliable feedback into the information systems of the status of work on site. Multiple research efforts have been made to automate monitoring of operations on site, with a view to supporting construction management. 
These have included monitoring of workers [31], monitoring of construction equipment, such as tower cranes [32], and scanning or image-recognition to identify work completed or as-built conditions [33]. However, the driving model for many of these is the notion of contract management rather than production management. They aim to measure actual performance and compare it to measured performance, so that appropriate corrective action can be taken where necessary. A better approach is to involve the people performing the work to provide status reports, but in ways that do not encumber them with additional tasks. The linkage of field software and hardware with BIM systems, such as that developed by Vela Systems and Tekla corporation [34], use RFID tracking and reporting from site personnel to update project status in real-time, achieve this by reading and interpreting data directly from hand-written forms filled in during the normal course of work.

\section{Goals and Method}

The goal of the KanBIM research as a whole is to propose, develop and test a BIM-enabled system to support production planning and day to day production control on construction sites. A system has been specified based on analysis of the literature on production control in construction, on the results of earlier research efforts $[25,35]$, and on study of production management practices in two major construction management firms (in London and Helsinki).

Since no comparable systems exist, and no existing software could be adapted for the purposes of evaluation of the proposed KanBIM system, the research method involved four steps:

a) Definition of the requirements;

b) Process analysis and system design;

c) Programming of functional mock-ups of its interfaces;

d) Evaluation of the system in focus group workshop evaluation sessions. 
In the first step, a set guiding principles was defined based on previous research and the literature. The principles were refined and elaborated through the experience gained in the following steps (steps c) and d) where iterated in three formal cycles).

System design began with preparation of a detailed 'future state' process flow map of the work flow envisaged for production planning and day to day production control on construction sites. The information system required to support the process was then derived, and defined in a system architecture plan. This step also required selection of the delivery methods (hardware) for each interface.

In step c), functional mock-ups were prepared for the main user interfaces. The mock-ups sought to provide sufficiently complete functionality to thoroughly demonstrate the system's intended modes of operation. These user-interfaces cover the stages of a) preparation by trades for weekly work planning meetings, b) negotiation between trade crews prior to and during weekly work planning meetings with the construction management team, and c) day to day interaction with trade crew leaders on the job site. Programming of the functional mock-ups served not only the evaluation step, but was in and of itself a formative activity in testing the assumptions made in defining the work flow and the system architecture, applying to them a rigor that could not have been achieved otherwise.

The user interfaces were evaluated in three focus group workshops which each involved construction managers, trade team managers, and team leaders. Two workshops were held in the UK and one in Finland. Qualitative rating-supported evaluation was preferred over a quantitative and entirely rating-based evaluation. The system was demonstrated to the participants, and they were then asked to complete a set of typical tasks using the large format touch-screen interfaces (as described in the 'System Development' section below). The need for hands-on interaction with the system for evaluation meant that surveys could not be used, so that assessment of the results was qualitative rather than statistical. 


\section{Requirements for BIM-based Lean Production Management Systems}

The requirements for development of a KanBIM system can be classified in seven main areas, which are detailed under the sub-headings below. There is some overlap between these, and the specific features of any given system are likely to satisfy multiple requirements.

\section{Process Visualization}

Despite the best efforts of project managers and planning teams, the uncertainty inherent in construction operations results in changes to work plans. Records of the 'percent plan complete' (PPC) measure covering multiple projects show that even where the LPS has improved the reliability of planning and operations, the PPC rarely goes above $80 \%$ [36], which means that some $20 \%$ of tasks are still not executed according to plan. This occurs despite their having been filtered for maturity in the weekly work planning process. As a result, when any task is not completed according to plan, dependent tasks are rendered immature.

To avoid propagating plan failure and the associated waste within the current planning phase (usually a week), trade managers and trade team leaders need both a) to be continuously informed of the current status of operations, and b) to have the ability to proactively change daily task assignments in close coordination with all parties that may be affected by the change. There is therefore a need to display the status and location of work teams and the real-time maturity of pending tasks. To support negotiation and reporting of plan changes on a daily level, a system must also provide mechanisms for communication and feedback of decisions - these are discussed below. Formoso et al. (2002) identified a number of additional benefits of process transparency that are relevant for construction, including: improving the effectiveness of production planning and control; increased involvement of workers in continuous improvement efforts, since it allows rapid comprehension of and response to problems; simplification of control; reduced propensity for errors by making them more visible; and improved motivation of workers. 
Russell et al. [37] highlighted the need for timely visualization of construction management data and reviewed various aspects of visual analytics. They present candidate views of data such as numbers of change orders within different context dimensions. However, like other visualization schemes in construction management (such as [38]), their primary target audience is project management, and the visualizations cannot communicate the current state of production on site (location of teams, production rates, stoppages and their reasons) to site personnel.

Evidence of attempts to display process information on drawings, such as the example shown in Fig. 2, can be found in construction site offices all over the world. However, given the changing physical reality of a construction job site, digital three dimensional views of building models provide a much better backdrop for displaying process status. The ability to manipulate BIM views to show information that is specifically filtered for any given viewer, including the ability to query visible objects for their relationships with work packages and their changing status through time, makes BIM an ideal medium for visualizing process if the product information is augmented with appropriate process object symbols.

\section{Product and Method Visualization}

BIM tools enable three and four-dimensional visualization of the building product. Effectively communicating design intent is one of its key functionalities and benefits. The weakest link in this communication is the 'last mile'; delivery of the product information to the workers during production, because it still relies on formal drawing views of the information that can be printed on paper. Electronic media offer the opportunity to deliver information in dynamic views that can be manipulated and queried by the consumers, including animations and database access. The challenge is to make product information ubiquitous at the workface without encumbering team leaders or workers with equipment that may hamper their comfort, safety or productivity. 
Various researchers have sought methods for this, including the use of mobile-phones, personal digital assistants (PDA), wearable computers, tablet PCs and other hardware. Lipman [39], for example, developed methods to deliver full scale fabrication models of steel buildings on PDAs. The 'i-booth' [26] provided a full size screen on which drawings could be displayed on site. The large format all-weather touch-screen monitors used for the KanBIM system (Fig. 8) do not impose physical restrictions on workers and they provide the essential function of online feedback, which is discussed below. They are also suitable for viewing by multiple team members, and could be used for screening 'animated method statements' during 'toolbox talks'.

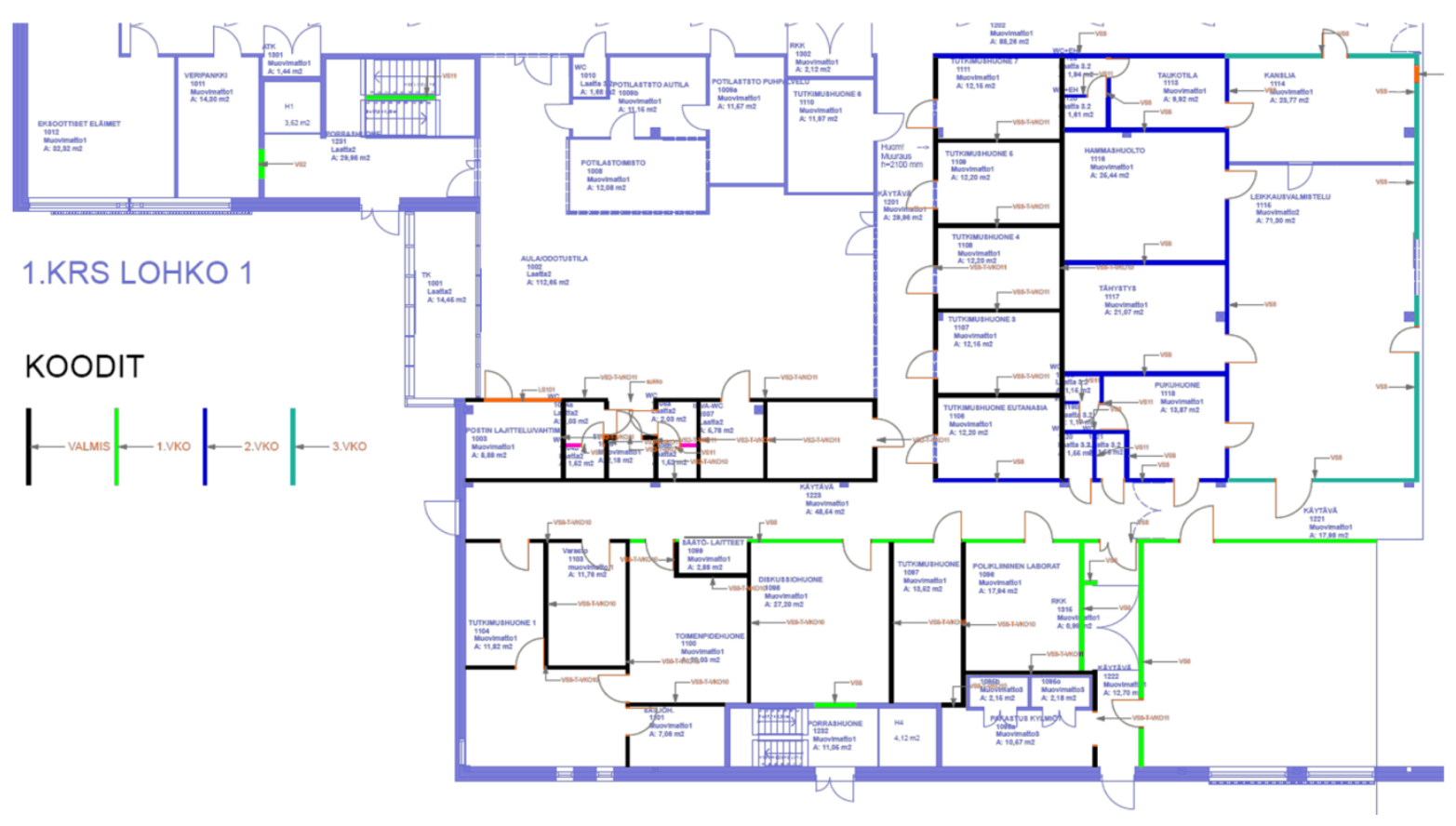

Fig. 2. Visualization of drywall tasks color-coded to identify process status, as used by a Finnish construction management company.

\section{Computation and Display of Work Package and Task Maturity}

We define 'maturity' to be a measure of the state of readiness of a work package or a task. It is an evaluation of the degree to which any constraints preconditions have been released. Unresolved preconditions may prevent imminent execution of a piece of work correctly, on time and with the expected level of resource consumption. As categorized by Koskela [1], they include preceding work, information, materials, equipment, team, space, external conditions. Others have proposed 
that safety requirements be added to the list. If the state of each of these constraints can be evaluated, a conjunctive 'maturity index' (MI) can be computed for any task at any given point in time. The maturity index is intended to support both short-term decision-making by team leaders, before they commit to performing tasks, and also to support weekly-planning activities. For planning, we are concerned with the predicted future value of the maturity of a task, which means that the calculation must consider a) the current status of the task's preconditions, b) the expected status at the time being considered for the task's execution, and b) the reliability of the predictions of the values, based on the recorded reliability of their sources in making those predictions. The maturity index is displayed to planners and team leaders using color-coded symbols on task icons, as shown in Fig. 4.

The maturity index for a task is calculated as a composite of the maturity measures of each of its distinct preconditions. The maturity measure for an individual precondition $j$ is a function of: the current status of the precondition $\left(S_{j}\right)$; the point in time for which the maturity is being calculated $\left(t_{M}\right)$; the point in time at which, according to the current plan, its supplier $k$ has committed to providing it $\left(t_{E}\right)$, and; the reliability of its supplier $\left(R_{k}\right)$. It is calculated using equation [1] as follows:

$$
M_{j}=S_{j}+\left[1-S_{j}\right\rfloor R_{k}\left(t_{M}-t_{E}\right)
$$

\section{Equation 1}

The status of a precondition reflects its degree of completeness at the time the calculation is made, but is also dependent on the nature of the precondition. Each precondition type may have a typical rule governing the way status should be assigned. For example, if $80 \%$ of a given material is already available, then its status will be 0.8 and the second half of equation 1 represents the probability that the remaining portion of material needed will be delivered by time $t$. On the other hand, if three drawings are needed and only two are complete, the status will be zero (because no work can be performed unless all of the drawings are available and complete), and the precondition maturity will reduce to $M_{j}=R_{k}\left(t_{M}-t_{E}\right)$. 
The reliability of a supplier $k, R_{k}$, is taken as the historical cumulative probability of the supplier fulfilling their commitment to supply the resource on time as measured according to their past performance. As a project progresses, the supplier's actual performance in meeting commitments is recorded, and a probability distribution accumulates. For example, if a flooring trade team has a record of meeting committed dates as shown in Table 1, then the reliability of the team completing a preceding task on the day before it has committed to finishing it is $18 \%$. If the team has already completed $60 \%$ of the preceding task when maturity is calculated, this precondition will have a maturity measure of $0.6+0.4 * 0.18=0.67$; the maturity measure for the day after that promised will be $0.6+0.4 * 0.73=0.89$. If the task has already been completed, the maturity $=1.0$ regardless of the reliability record, because the status is $100 \%$.

Table 1 . Supplier reliability $R_{k}$ based on its record of project performance to date.

\begin{tabular}{|c|c|c|c|c|}
\hline \multicolumn{2}{|c|}{$\begin{array}{l}\text { Performance record } \\
\text { (actual date - plan date) }\end{array}$} & Frequency & $\begin{array}{l}\text { Cumulative } \\
\text { frequency }\end{array}$ & $\begin{array}{l}\text { Percentage } \\
\text { cumulative } \\
\text { frequency }\end{array}$ \\
\hline-4 & \multirow{4}{*}{ Early } & 0 & 0 & $0 \%$ \\
\hline-3 & & 0 & 0 & $0 \%$ \\
\hline-2 & & 1 & 1 & $9 \%$ \\
\hline-1 & & 1 & 2 & $18 \%$ \\
\hline 0 & On time & 4 & 6 & $55 \%$ \\
\hline 1 & \multirow{5}{*}{ Late } & 2 & 8 & $73 \%$ \\
\hline 2 & & 2 & 10 & $91 \%$ \\
\hline 3 & & 0 & 10 & $91 \%$ \\
\hline 4 & & 0 & 10 & $91 \%$ \\
\hline 5 & & 1 & 11 & $100 \%$ \\
\hline
\end{tabular}

Once the MI module has computed the maturity measures for all preconditions, they must be combined in a way that is meaningful for users. A composite graphic of eight Mls may be presented, one for each precondition type. In this case, the overall value for each type is the minimum value of the maturity measures for all of the preconditions belonging to that type. The resulting maturity index calculation is: 
$M I=\sum_{j} M_{j} W_{j} W_{M j} / \sum_{j} W_{j} W_{M j}$

The weightings here have two parts: $W_{j}$, which represents the relative importance of the precondition, and $W_{M j}$, which is used to give greater weight to lower values, thus placing the result somewhere between the simple average and the minimum value. This can be done with different formulae to calculate $W_{M j}$, such as:

$W_{M j}=1-M_{j} / 2$ or $W_{M j}=1-M_{j}$ (to amplify lower values) or $W_{M j}=1$ (for a simple average).

Alternatively, a single normalised MI value may be presented for a task, computed as a weighted average of the individual maturity measures or as an average of the eight results for the precondition types.

A further consideration in calculating overall task Mls is that they are predictions of future states. Given that trade team leaders and managers compare among them to select most mature tasks, $\mathrm{MI}$ values for earlier tasks should reflect a greater degree of confidence than that placed in more distant predictions. We note also that for any given point in time, the cumulative distribution value does not reflect the pattern of the distribution itself. This can be problematic where a distribution has a long tail of late values because it hides the degree of impact of the risk involved in delayed delivery. A more sophisticated version of the calculation is under consideration in the framework of ongoing research where measurements of actual performance are being collected to enable evaluation and calibration of maturity index forecasts. These and other aspects, including calibration of MI computations against empirical evidence, and trade crew leaders' perceptions of the MI value presented to them, will be reported in detail in a separate paper.

\section{Support for Planning, Negotiation, Commitment and Status Feedback}

Part of the reason for the dearth of state of the art information systems to support production management described above is insufficient recognition of the fact that the conceptualizations used to represent and plan construction work at the planning level of resolution do not apply at the 
production level. The underlying assumption behind the network planning approach and the critical path method (CPM) is that work can be packaged into distinct activities and that technological constraints (such as 'finish-start') can be strictly applied between them. However, these relationships break down at the level where they can be negotiated between small work teams. For example, a construction plan may call for all ducting work in a zone to be completed before sprinkler installation begins. Yet with appropriate discussion between the two team leaders, the work can often proceed in parallel, with duct work preceding sprinkler pipes in some spaces within the zone and following it in others. Even where technical precedence does apply, the relationships change as the granularity of planning increases, as can be seen in Table 2, which compares different aspects of construction planning for three levels of detail. A construction production system must recognize the dichotomy and provide functionality that supports the people involved to negotiate the relationships and prepare conflict-free and coordinated work plans at the weekly and daily levels, without being encumbered by the conceptual constructs of the network planning approach.

Table 2. Aspects of construction planning and control according to level of planning.

\begin{tabular}{|l|l|l|l|}
\hline \multicolumn{1}{|c|}{$\begin{array}{l}\text { Planning } \\
\text { Level }\end{array}$} & Master Planning & Look Ahead Planning & Weekly Production Control \\
\hline Resolution & Milestones & Work Packages (activities) & Tasks (assignments) \\
\hline Goals & $\begin{array}{l}\text { Define contract } \\
\text { packages }\end{array}$ & $\begin{array}{l}\text { Make work packages ready; } \\
\text { release constraints }\end{array}$ & $\begin{array}{l}\text { Manage flows of people, } \\
\text { material, work, information, etc. }\end{array}$ \\
\hline $\begin{array}{l}\text { Methods for } \\
\text { definition of } \\
\text { planning unit }\end{array}$ & $\begin{array}{l}\text { Top-down division of } \\
\text { project duration }\end{array}$ & $\begin{array}{l}\text { Top-down division of } \\
\text { milestones into activities }\end{array}$ & $\begin{array}{l}\text { Bottom-up aggregation of parts } \\
\text { into a task }\end{array}$ \\
\hline $\begin{array}{l}\text { Tools and } \\
\text { measures }\end{array}$ & $\begin{array}{l}\text { Contract terms; } \\
\text { Critical path method; } \\
\text { process optimization }\end{array}$ & $\begin{array}{l}\text { Critical path method; constraint } \\
\text { release; maturity index; line of } \\
\text { balance scheduling }\end{array}$ & $\begin{array}{l}\text { Pull priority; negotiated team } \\
\text { coordination; maturity index } \\
\text { (provided in KanBIM) }\end{array}$ \\
\hline Relationships & Contractual & $\begin{array}{l}\text { Hard technological constraints } \\
\text { (such as FS); Resource leveling } \\
\text { and space conflict resolution }\end{array}$ & $\begin{array}{l}\text { Flexible working relationships/ } \\
\text { resource and space coordination }\end{array}$ \\
\hline $\begin{array}{l}\text { Primary } \\
\text { planning } \\
\text { responsibility }\end{array}$ & $\begin{array}{l}\text { Construction } \\
\text { manager }\end{array}$ & $\begin{array}{l}\text { Construction manager in } \\
\text { consultation with trade team } \\
\text { managers }\end{array}$ & $\begin{array}{l}\text { Trade team leaders and } \\
\text { managers }\end{array}$ \\
\hline
\end{tabular}

In production systems where uncertainty is high and conditions may change, 'agility' is needed [40].

In the construction context, this means that responsibility for making a final commitment to actually 
begin performing a task must reside with the team leader, who retains some flexibility. Where a planned task has become 'immature', the team leader must be able to respond by selecting a predefined contingency task or by negotiating a change of plan with all those who may be affected. To support this degree of agility without maintaining excess capacity, a robust information system is needed to enable good decisions to be made quickly. To do this, the system must:

- tightly integrate planning and production control. The granularity of the weekly work planning and the level of detail of task properties must be appropriate for daily production control;

- enable online feedback from the workface to ensure that the process status information is up to date;

- provide a channel of communication for negotiation of changes to planned tasks. Reducing the planning window to daily level, extending the Last Planner System, requires enabling trade team leaders to propose plan changes, identify and resolve any resulting conflicts through negotiation with the affected parties, and inform all other project participants of the resulting changes.

The language/action perspective [41], which expresses the idea that activity in projects is coordinated through making and keeping commitments rather than by directives from managers to those responsible for executing work, has been identified as an important potential contributor to achieving plan reliability in construction supply chains [42]. It defines a process of request, commitment, action and reporting completion. A KanBIM system must implement this explicitly at two levels:

a) Weekly work planning. Initial requests are communicated to trade teams in the form of work packages scheduled in the look ahead plan. Trade teams then need to define the detailed tasks for each work package, schedule them in a weekly work plan, negotiate with the other teams and the construction management functions to remove conflicts of space and resource use, and finally express explicit commitment to the coordinated plan. 
b) Daily work execution. Team leaders must be able to select a mature task for execution, reaffirm commitment to completing it at the time work begins, and then report completion of the work once it has been done. In cases where a task cannot be completed, the system should require explicit declaration that work is stopped and a detailing of the reasons for stopping. This communication can be facilitated using touch screens (as shown in Error! Reference source not found.a), or other devices such as cell phones.

The mechanism for reporting start and completion or stoppage of tasks is crucial because it provides the feedback which allows the system to remain up to date with events as they occur on site. Reporting stoppage is also essential because it supports ANDON style signals, pushed automatically by the system via SMS and/or email, that can alert designers and/or managers to a production problem as it arises.

Embedding the language/action perspective in a KanBIM system also applies the principle that work planning and coordination is a human endeavor and that the purpose of the software is to support negotiation and decision making by people. As such, a system should alert users to any planning conflicts, but it should not take action at any step where value judgment, context awareness or commitment to act is required. It should empower people and facilitate direct discussion between them, leading - as far as possible - to creative collaborative control at daily level instead of central control.

At the same time, we recognize that final authority for resolving planning conflicts must lie with the project's construction manager, who must be the final arbiter of task assignments and priorities in the weekly work plan. This need arises because, by definition, the best weekly work plan, optimized for the project as a whole, will be sub-optimal for some of the trade teams. 
Requirements for Building Information Modeling based Lean Production Management Systems for Construction Accepted 2/2010 for Automation in Construction

(C) 2010 Sacks, Radosavljevic, Barak

\section{Implement Pull Flow Control}

An online process status display can be used as a means to communicate pull signals to work teams in situations where more than one task is possible at any given time. In most construction projects, it is not possible to achieve a true pull flow regime, because construction does not have steady state production systems with continuous flows of similar products. In construction, we build the production facilities (site offices, cranes, support structures, etc.) at the same time as beginning to build the 'products', and begin dismantling the production facilities before the first products are delivered. The 'factory' operates in start-up mode, and usually does not reach full saturation (i.e. the first product is not completed) before dismantling of the first-used facilities is begun.

It is possible, however, to apply a conscious strategy to reduce the quantity of work in progress, i.e. to reduce the number of spaces being worked on simultaneously [43]. In construction, spaces (rooms, apartments, etc.) can be considered the products; the building as a whole is an aggregate product. The strategy, termed 'WIP reduction', requires trade teams to place highest priority on tasks that complete their work in spaces (where work has already begun) soonest, and lowest priority on tasks that begin work in new spaces. The approach is directly comparable to the controlled WIP (CONWIP) strategies used in manufacturing situations where pull flow cannot be applied directly [13]. It is generally not subcontractor trade teams' strategy of choice, because it does not leave them flexibility to switch workers to alternative spaces when work must be stopped in a space for any reason (a common occurrence on less stable projects). Nevertheless, experiments using discrete event simulation have shown that the positive effect on cycle times of spaces and on total project durations are significant [43], because the strategy works to enhance overall project optimization rather than local task optimization.

The strategy can be applied by each team individually, but it could also be extended to encompass multiple trades if, at any given time, the probability of achieving a smooth workflow to complete each space, over a series of tasks by multiple teams, could be computed and compared with the 
probability of smooth completion of other spaces. The short-term tasks in the space with the highest probability for smooth work to completion would be given highest priority for its next trade. We call this probability the 'pull flow index' (PFI), and define it as "a measure of the likelihood that the sequence of tasks following the current task, that is needed to complete a zone or product, can be performed continuously to completion." In practical terms, the PFI for a pending task in a space is a function of the maturity index values of the string of tasks that is required to complete that space. Those maturity indices are themselves functions of their precondition maturity measures, as defined above, which are in turn functions of the expected date of each precondition and the reliability record of its supplier. Since maturity index values are predictions of expected future conditions, their reliability declines in inverse relation to the time between their prediction and the planned execution of the tasks for which they are computed.

The PFI would be used by construction managers when setting task priorities, which must be done with respect to both the need for controlling WIP and to other project imperatives. The priority levels they set must then be communicated to teams on site. Communicating the pull flow priority to teams is straightforward where teams have ubiquitous access to real-time information about project status; it is expressed using star ratings on the task icons in Fig. 4. An additional visualization benefit of the task icons is that they make it possible to see the quantity of work in progress, simplifying management of a WIP reduction strategy. A project manager could elect to control and limit the number of tasks that a team leader is 'offered' or may have under way at any one time, thus implementing the CONWIP approach.

To buffer the effects of potential work stoppages under the WIP reduction strategy, a set of contingency tasks should be included in every team's weekly work plan. As far as possible, these should be independent of other trades (no shared equipment, no shared space, etc.). Contingency tasks are not scheduled to a particular day in the weekly task plan. They introduce short-term flexibility and are marked appropriately on the task icons. 
Requirements for Building Information Modeling based Lean Production Management Systems for Construction Accepted 2/2010 for Automation in Construction

(C) 2010 Sacks, Radosavljevic, Barak

\section{Maintain Work Flow and Plan Stability}

Achieving stable workflow is the basic method for minimizing waste of labor time in construction.

Stability is not only important directly, it is also the basis for methodical process experimentation ('management by testing of hypotheses'), which is a key tenet of the Toyota Production System [11]. In the LPS, the 'percent plan complete' measure is used to help project organizations learn about the reliability of their plans and thus improve plan stability, but, as explained above, it is a retrospective measure.

The need for plan stability implies some guidelines for production management using a KanBIM system. 'On the fly' changes to the content of tasks (expressed as aggregations of building product objects in the construction model) are not to be allowed during the week; a failure due to unavailability of a part or error in its fabrication or design information should be revealed, not hidden by removal of the part from the task definition. Even when tasks planned for a day are complete, the starting of tasks scheduled for future days should not be permitted, except after coordination with other trades and suppliers within the KanBIM system, because what is not planned and recorded in the system cannot be measured. The pitfalls of potential negative impacts on other trades and the danger of 'making-do' and subsequent rework mean that plan changes must be negotiated and recorded.

\section{Formalize experimentation for continuous improvement}

The principles that Deming developed for statistical analysis of production quality [44] are the basis for the formalized approach to continuous improvement described in the previous section. The KanBIM system can institutionalize this approach by allowing planning teams to select one or more specific tasks for structured experimentation in each weekly work plan, as proposed in the PPM. The task selected(s) would be marked with an appropriate icon and carry a data record defining the goal of the experiment, the changes proposed to the work method, the method and units of measurement of results, and a definition of success or failure. Computerization in this case has the 
benefit that if an improved work method is adopted, the recipe can be embedded in the routines that generate tasks for task planning.

Formalized experimentation could then lead to continuously improved work methods that can be carried over to future tasks of the same type and to future projects, with wide ranging benefits for various project stakeholders. For instance, with continuous improvement being part of the weekly planning, task level innovations may become a key source of competitive advantage for trade contractors.

\section{KanBIM Planning and Control Process}

The KanBIM concept seeks to leverage the detailed product information that is available in building information models to support fine-grained operational coordination on construction sites. It is based on the LPS [5] and the Process Planning Methodology (PPM) [35], but extends both in numerous ways. The process chart shown in Fig. 3 describes the actors in construction site production management, the information they each generate, a set of 'activity scenarios' in which information is generated, and the way the information is distributed and recorded in the different information repositories maintained by the actors. The process starts with the creation of a Master Plan. In this stage the users compile and maintain a set of high-level activities and subordinate work packages, and schedule them, including trade assignments and buffering. High-level resource leveling must also be done for major equipment and spaces. This is done using existing construction planning tools.

The next stage (activity 2 in Fig. 3 ) is look ahead planning. It consists of breaking down the high-level activities into smaller, manageable work packages, defining logistic and engineering constraints in the form of connections between activities (i.e. finish-start, finish-finish etc.) and assigning equipment and materials. The master plan and the look ahead plan both are done by managers of the general contractor (or construction management company) and the principal work package 
subcontractor managers. Both of these stages are the same as standard LPS, with only one additional requirement, which is that they are prepared using a BIM interface in which building elements are associated with the activities. This capability, available in the existing commercial software described above, allows integration of the product model with the high-level process model.

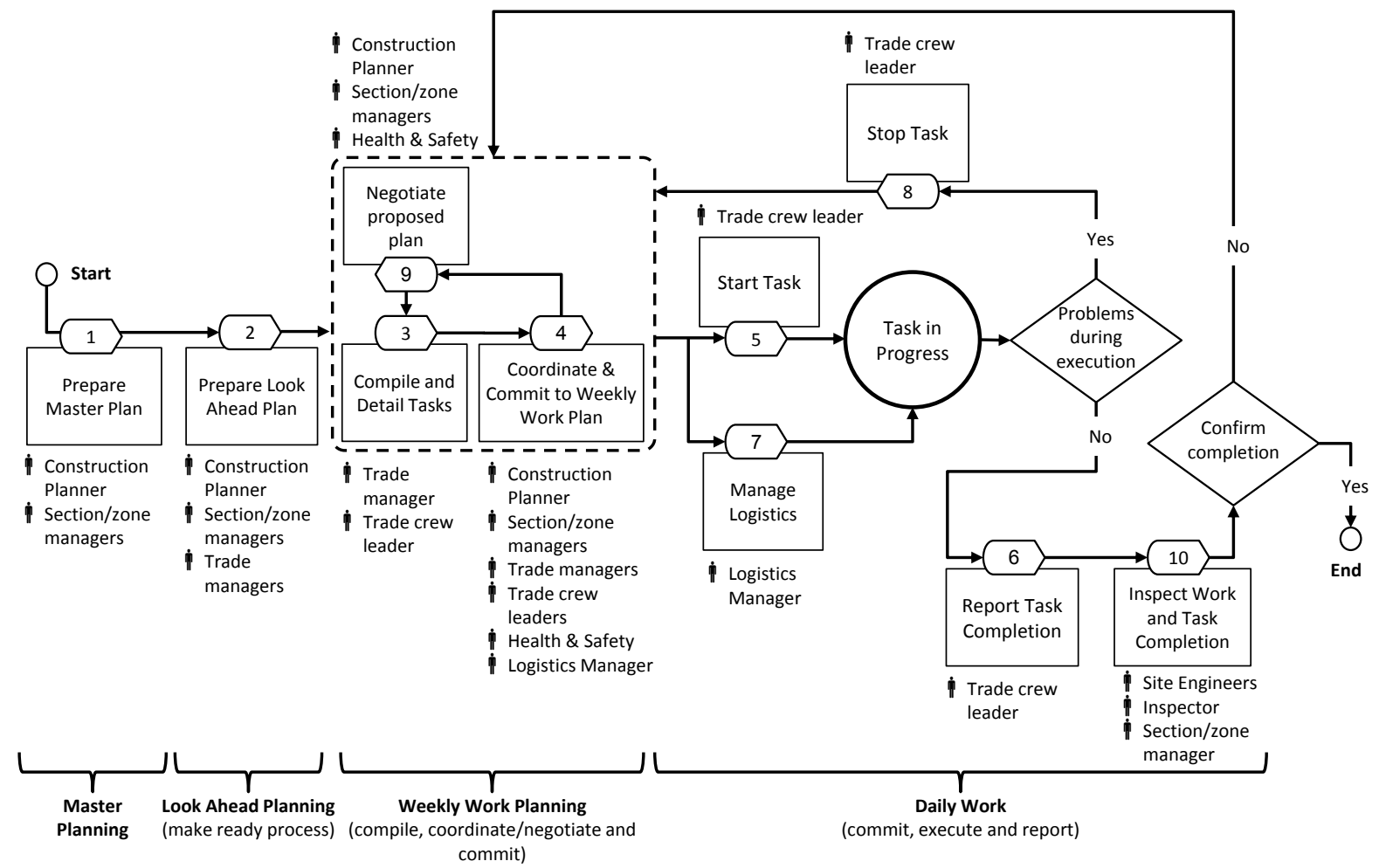

Fig. 3. Process flow model for the KanBIM system.

The next step of the LPS process, weekly work planning, is divided here into two stages. First, in activity 3 in Fig. 3, each trade crew details its work packages into a set of candidate tasks that it can perform during the following week, in preparation for the weekly work planning meeting (activity 4 in Fig. 3). This activity starts with a set of candidate work packages that were drawn from the look ahead plan according to their planned start date and priority. Each work package contains a set of 'task types' representing the different kinds of work needed to perform it according to the production method. For example, in order to erect a drywall, the following tasks are needed: build the wall frame; close the first side with plaster boards; place insulation materials and fix any mechanical, electrical or plumbing (MEP) embeds; close the second side with boards; and apply joint 
strips, sand and paint. BIM objects can require one or more task types and the associations are recorded with the object's properties.

The work packages are shown using symbols and highlighted object groups in the model. The trade contractor's manager and his or her crew leaders divide the work packages into candidate tasks by selecting a subset of building elements from the work package elements and grouping them into distinct tasks according to their task types. For easier selection and better control of the overall process of dividing the work packages into tasks, all building elements that have not yet been allocated to tasks are labeled 'unassigned' and highlighted appropriately. The user interface to support this activity is shown in Fig. 4, which shows a hierarchical work package/task type/task tree, a view of the building model focused on the work package zone and elements with symbols representing its tasks, and a weekly schedule planning area at the bottom of the screen. Tasks are scheduled and assigned to crews by dragging their symbols to the rows of specific crews on specific days. In addition to tasks created and assigned by the trade manager, there are also two kinds of special tasks: tasks that the trade manager assigns to other supporting trades and tasks that are assigned to this trade subcontractor by other trades. These tasks need to be assigned to crews in order to become part of the weekly work plan, in a negotiated process that is explained below. Since each trade contractor creates its own proposed weekly work plan, the plans need to be synchronized and finalized to form a mutually agreed project-wide work plan. This is done in a weekly work planning meeting (activity 4 in Fig. 3 ) that is directed by the project planner and in which all trade managers participate. The meeting setup is illustrated in Fig. 5. During the meeting the project planner reviews the candidate work packages and tasks for promotion to approved tasks for the coming week. The interface for this activity is presented on two large screens: a data view (shown in Fig. 6) and a corresponding model view. The two screens are merely different representations of the same content (one alphanumerical and the other graphical) and any operation on one, is automatically reflected in the other. For example, when a task is selected in the 
data view the model view will focus on and highlight its building elements and show temporary equipment; or when the tasks are filtered in one view (by date, space, contractor etc.) the other will show the same results. The interface allows the users to switch between four different aggregation data views (tasks sorted by contractors, work packages, spaces and shared equipment) to eliminate any clashes and to improve plan reliability.

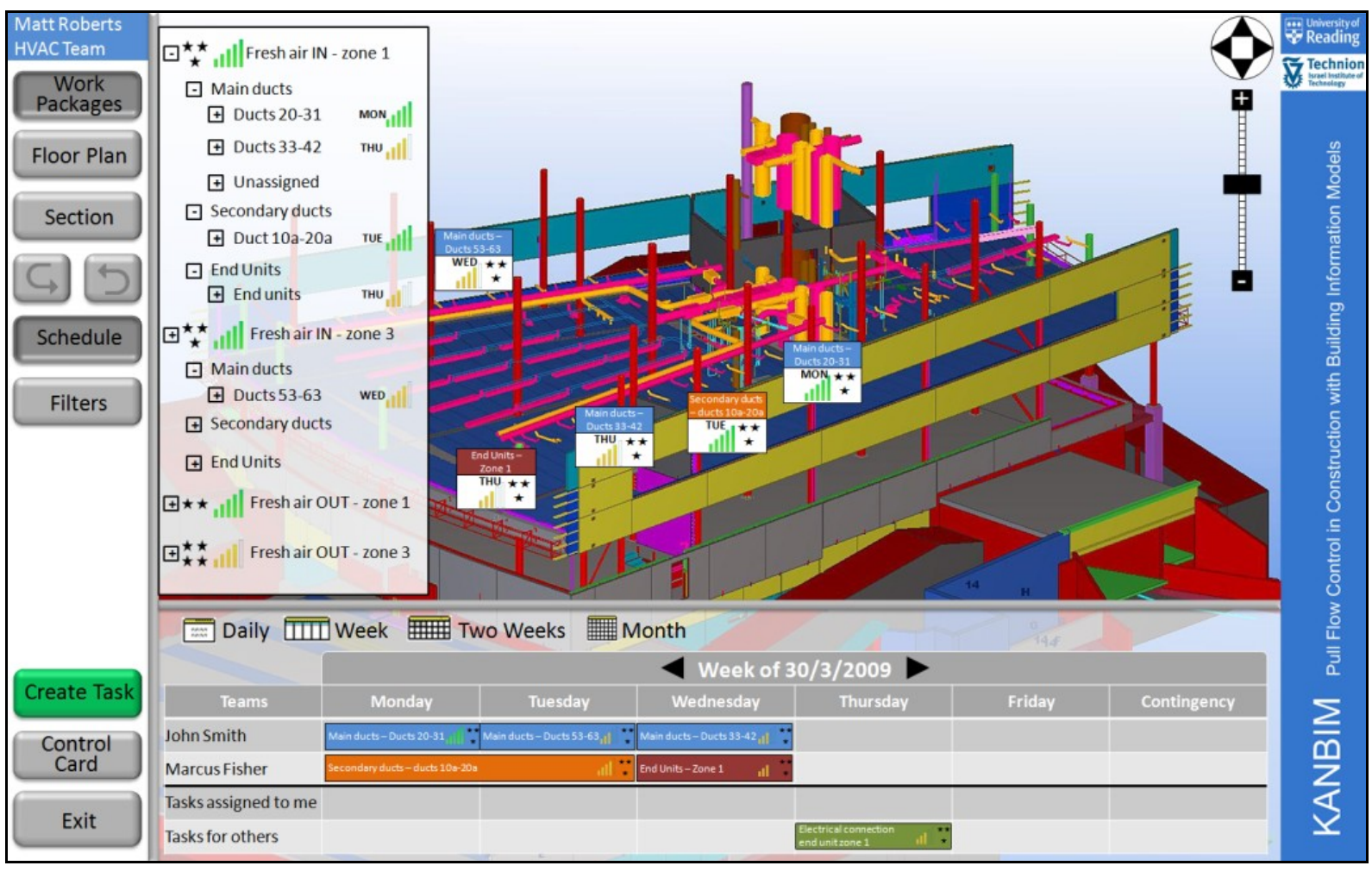

Fig. 4. User interface for detailing work packages to tasks and compiling the weekly work plan by allocating crews to tasks
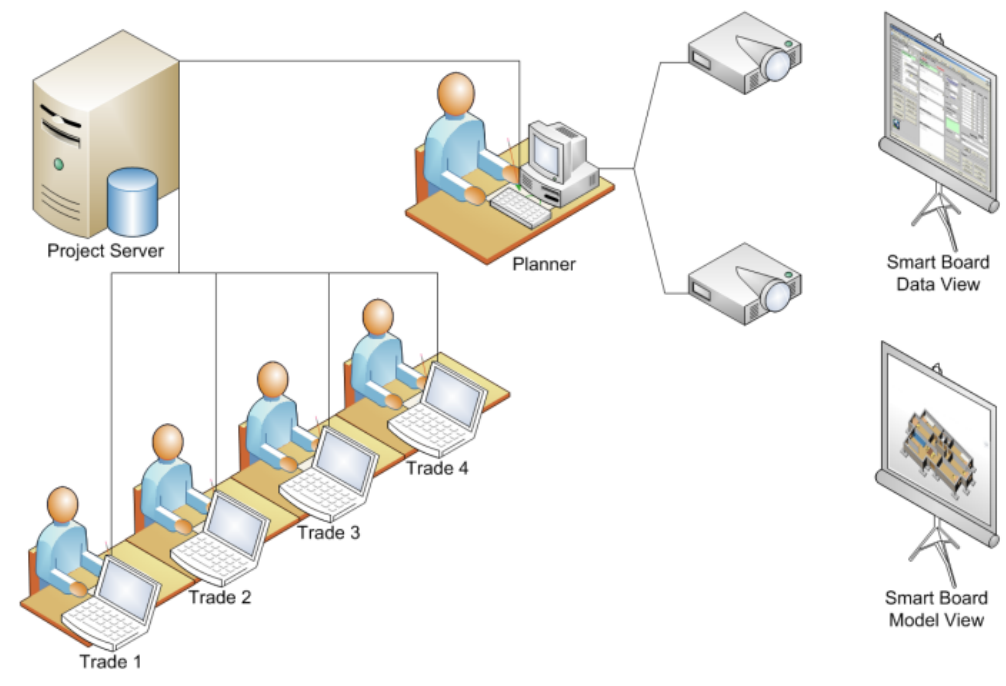

Fig. 5. Weekly work plan meeting setup 
Any conflicts identified must be resolved through discussion and coordination between the relevant trade managers. To resolve conflicts they can change their proposed plans using the same interface used for initial planning (Fig. 4). Changes could include rescheduling tasks, assigning more crews or workers, changing resources by changing construction methods, and others. The changes are made while all the participants are online so that the project planner views will reflect the changed overall weekly work plan.

After applying changes to the plan to make it feasible and acceptable for all the 'last planners', each of them must explicitly accept their part of the plan and commit to executing theirs tasks. Plan acceptance is shown on the project planner interface and only when a group consensus is achieved is the weekly plan approved as a whole.

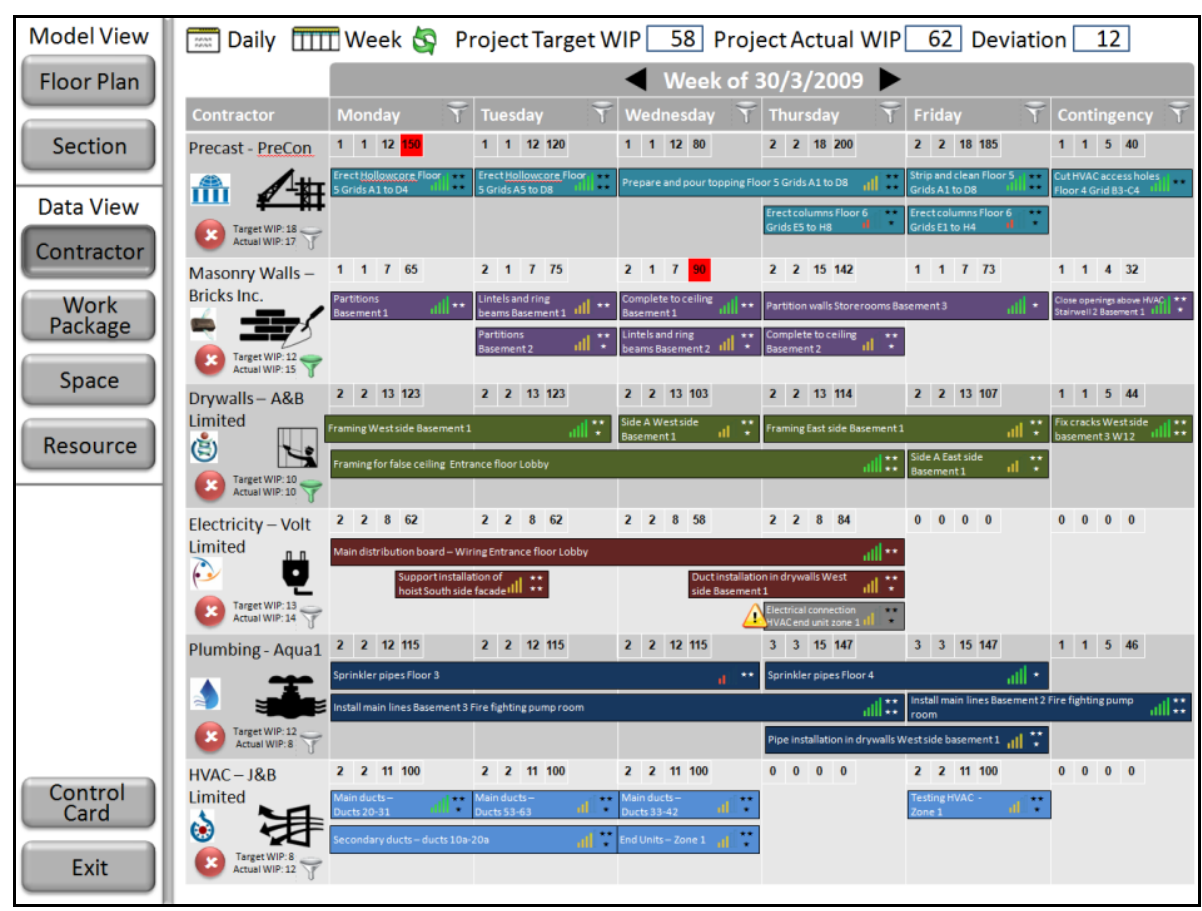

Fig. 6. Project planner contractor view interface for creating integrated and synchronized weekly work plans. The next level of planning takes place on a daily basis, concurrently with execution of the work through each week. This is the heart of the KanBIM process, where the crew leaders are given direct access to the work plan and empowered to coordinate their work with all other crews as and when needed (activities 5, 6 and 8 in Fig. 3). The specialized model interface (shown in Fig. 7), which shows 
each crew leader's specific tasks, is delivered via a large scale touch screen (see Fig. 8). This interface not only delivers process and product information on demand, it also collects process information in real-time. Crew leaders use it to report the start of tasks as they are begun, to update ongoing tasks according to actual performance, to report that they have stopped work on a task and report the problem that caused the stoppage, and to report completion of finished tasks.

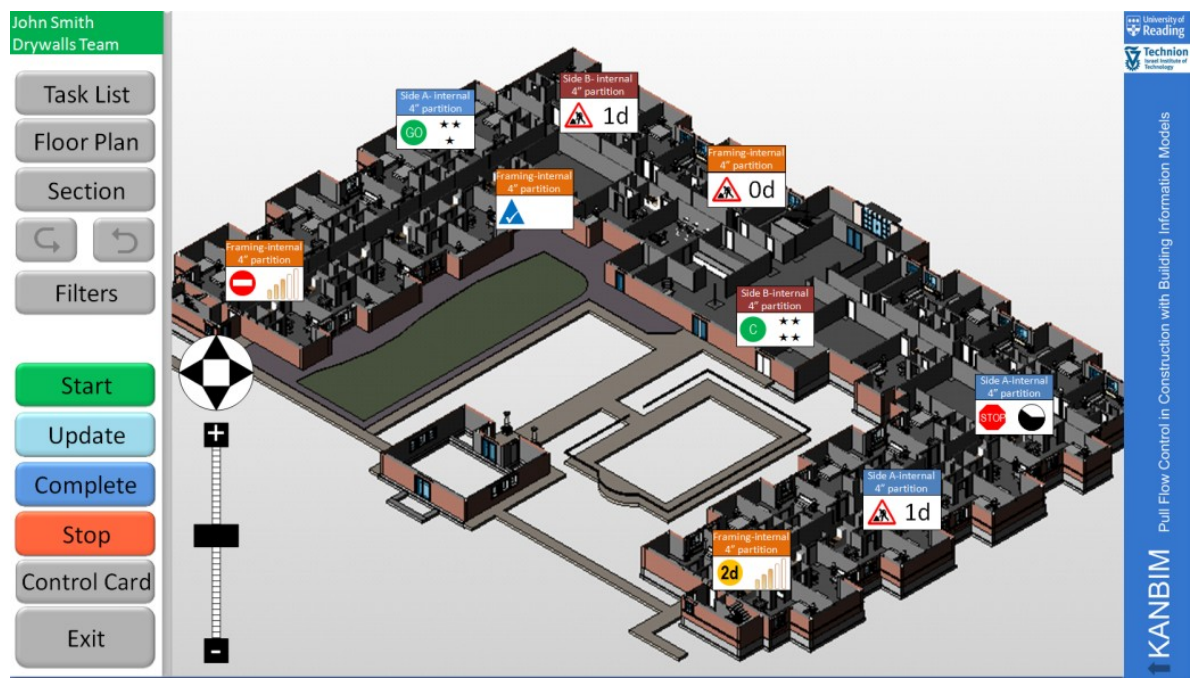

Fig. 7. Trade crew leader work status and reporting interface showing a crew's tasks. The crew leader can ask the system to show neighboring tasks for a complete picture of the overall work.

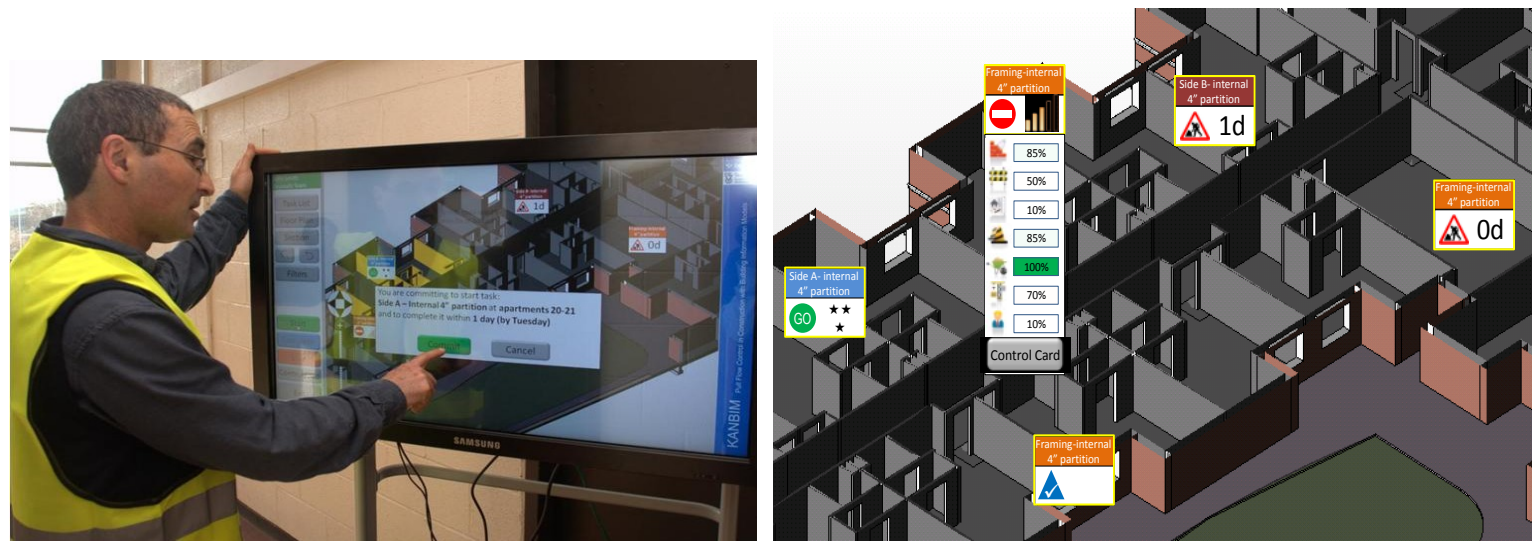

Fig. 8. Reporting start of a drywall activity on a building model interface using a 40" all-weather touch-screen monitor mounted on a mobile trolley. The system identifies trade crew leaders (by RFID tag or by entry of a unique ID) and delivers specifically tailored information concerning their tasks' status and content.

Problems that adversely affect execution, such as unavailable equipment, can be reported together with details that enable responders to resolve them, such as details of which specific piece of equipment is malfunctioning or missing, as shown in Fig. 9. In this way crew leaders can also report 
design issues directly on the model by using graphic annotation tools and voice messages. The production management server can alert those responsible for solving the issue according to a predefined work flow and create action items for fixing it. In the event that a crew leader needs to change the execution sequence of his/her tasks, they can use this screen to initiate dialog to negotiate the changes with the project planner and any other relevant crew leaders, in order to maintain overall plan stability.

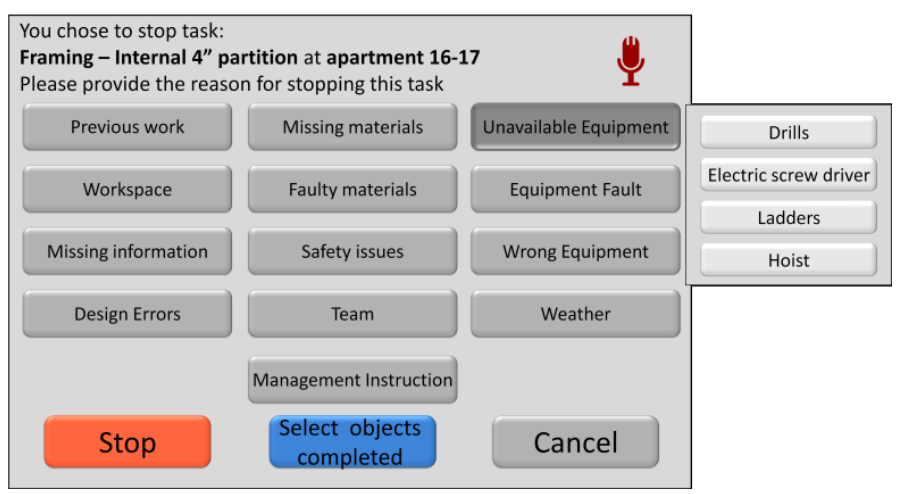

Fig. 9. Reporting form for problems during execution which led to stopping the task. The reporting tool enables information flow from the work face back to the information servers to create an up-to-date image of the work status and to raise flags when problems are encountered.

For learning purposes and to improve project performance, when a task is reported complete crew leaders are asked to report any difficulties even if the task was completed as planned. By pressing the complete button, the crew leader is also pulling an inspector to approve the completion of the task (activity 10 in Fig. 3). If the task completion is rejected, the rework needs to be re-scheduled by the project planner and the trade manager.

The information for each task is organized in a 'control card' according to seven pre-conditions and constraints: preceding activities, workspace, information (designs and specifications), safety, materials, equipment and crew. For each pre-condition an independent maturity index is calculated based on the constraints release status. An example of part of a task control card can be seen in Fig. 10 , showing the materials needed for framing drywall partitions in a specific workspace. In this example there are insufficient studs, and hence the maturity index for this pre-condition is less than 
$100 \%$. In a similar manner the maturities of all other pre-conditions are calculated and the overall task maturity index is evaluated, as can be seen at the left of the figure.

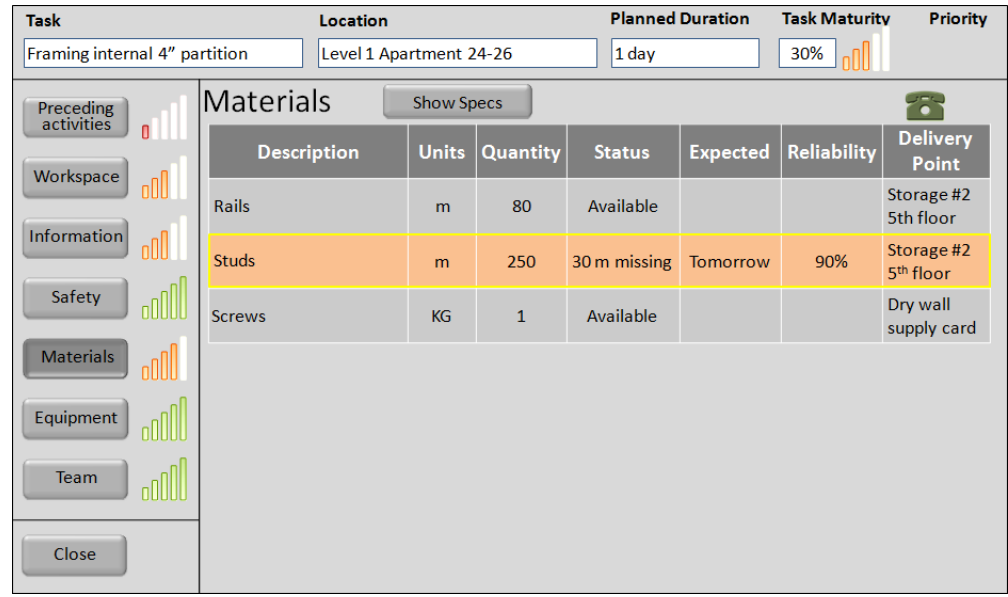

Fig. 10. Control card for framing drywall partition task

\section{Evaluation}

The functional mock-up user interfaces were evaluated in three focus group workshops held in the UK and in Finland with construction managers, trade managers and crew leaders. The first workshop predominantly focused on features and functionality of the user interfaces. After a round of improvements, the second and third workshops investigated to what extent the proposed system addresses existing production management problems.

The first workshop comprised four distinct stages:

1. Introduction of production management issues in construction including the discrepancy between linear CPM-based mental models and the more complex reality of intertwined resource and information flows.

2. Demonstration of the KanBIM mock-up system through the detailed stages of construction planning and production (activities 3-6, 8 and 9 offig. 3).

3. Open discussion of the potential discrepancies between the presented model and issues and real life situations. 
4. Evaluation of the system through a structured questionnaire (see Table 3 ) and group discussion that included a general evaluation of the proposed system followed by specific evaluation of the procedures and constraints.

The first workshop attracted 23 individuals from seven companies. 17 attendees (74\%) were from construction contracting companies, two (8\%) from consulting companies and four (14\%) were mature employer-sponsored postgraduate students. A summary of feedback corresponding to the evaluation criteria used in this workshop is presented in Table 3.

Table 3. Summary of evaluation criteria and feedback from the first workshop.

\begin{tabular}{|c|c|c|}
\hline Topic Evaluated & Evaluation Criteria & Feedback Summary \\
\hline $\begin{array}{l}\text { Day to day } \\
\text { operations: activities } \\
5,6 \text { and } 8\end{array}$ & $\begin{array}{l}\text { Importance of the availability of product/process } \\
\text { information for team leaders } \\
\text { Effectiveness, practicality and usefulness of touch screens } \\
\text { for gathering process information from team leaders and } \\
\text { how does it compare against PDA, tablet PCs, smart } \\
\text { phones and wearable computers } \\
\text { Potential for waste minimization as a result of available } \\
\text { information through a control card } \\
\text { Practicality of associating tasks with objects in the BIM }\end{array}$ & $\begin{array}{l}\text { Product/process information vital for team } \\
\text { leaders to successfully complete the work. } \\
\text { Practicality questionable due to security and site } \\
\text { conditions; tablet PCs are viewed as equally } \\
\text { practical but touch screens are more practical } \\
\text { than PDAs, smart phones and wearable PCs. } \\
\text { Control card found as a useful mechanism to } \\
\text { minimize waste. } \\
\text { 3D BIM-based representation is very useful }\end{array}$ \\
\hline $\begin{array}{l}\text { Preparation of } \\
\text { detailed weekly plan: } \\
\text { activity } 3\end{array}$ & $\begin{array}{l}\text { Importance of enabling trade managers to assign tasks by } \\
\text { work packages as defined in the look-ahead plan and } \\
\text { suggest a plan to be finalized jointly with other trade } \\
\text { managers in detailed weekly planning (Scenario } 2 \text { ) } \\
\text { Usefulness of the approach to assign and then drag-and- } \\
\text { drop assigned tasks into a suggested schedule of activities }\end{array}$ & $\begin{array}{l}\text { Early involvement of trade managers in the } \\
\text { planning process is very important providing an } \\
\text { opportunity to allocate tasks based on trade } \\
\text { optima. } \\
\text { Drag and drop assignment is very useful but there } \\
\text { should be an option to undo actions. }\end{array}$ \\
\hline $\begin{array}{l}\text { Negotiation of } \\
\text { detailed weekly plan: } \\
\text { activities } 4 \text { and } 9\end{array}$ & $\begin{array}{l}\text { How well does the suggested planning process follow } \\
\text { actual processes } \\
\text { How useful is the proposed detailed weekly planning } \\
\text { procedure (trade managers to view a suggested collective } \\
\text { schedule that can be filtered by contractor, work package, } \\
\text { space, resource and days of week; confirming their } \\
\text { commitment) }\end{array}$ & $\begin{array}{l}\text { They follow real-life situations well but more } \\
\text { room should be given to potential problems. } \\
\text { Collective detailed weekly planning is a very good } \\
\text { mechanism to identify and iron out } \\
\text { issues/clashes, improve tasks/processes and } \\
\text { acquire commitment from all involved trade } \\
\text { contractors. }\end{array}$ \\
\hline
\end{tabular}




\begin{tabular}{|c|c|c|}
\hline $\begin{array}{l}\text { Interfaces for day to } \\
\text { day operations: } \\
\text { activities } 5,6 \text { and } 8\end{array}$ & $\begin{array}{l}\text { How effective and efficient are "Start Task", "Complete } \\
\text { Task" and "Stop Task" procedures from a team leader's } \\
\text { perspective (e.g. instructions, icons, symbols, buttons and } \\
\text { their position) }\end{array}$ & $\begin{array}{l}\text { All procedures are easy to follow but there could } \\
\text { be more options and icons depicting processual } \\
\text { task-related information }\end{array}$ \\
\hline Control Card & $\begin{array}{l}\text { How effective and relevant is the Control Card in providing } \\
\text { a detailed overview of preceding activities, space, } \\
\text { information, H\&S information, materials, plant \& } \\
\text { equipment and crews }\end{array}$ & $\begin{array}{l}\text { Control card is indispensable for presenting task- } \\
\text { related process information but it is unclear how } \\
\text { the maturity and pull-flow indexes are to be } \\
\text { obtained. }\end{array}$ \\
\hline Symbols and Icons & $\begin{array}{l}\text { How well do the selected symbols and icons visualize } \\
\text { underlying information (e.g. tasks in progress, completed } \\
\text { tasks, pull-flow index, maturity index and control card } \\
\text { constraints) }\end{array}$ & $\begin{array}{l}\text { Most symbols are very clear because they are } \\
\text { already well known, with the exception of the } \\
\text { contingency task symbol and maturity-index } \\
\text { symbols. }\end{array}$ \\
\hline
\end{tabular}

The feedback from the first workshop did not reflect any particular difficulties with using Start, Complete and Stop procedures. Most of the practitioners agreed that interfaces could be enriched with additional menu items and symbols. The participants feared that team leaders might somehow become isolated from the rest of the project team if touch screens became a major point of interaction, and some suggested setting up additional meetings to avoid isolation. This is not unexpected, since successful problem-solving as we know it in construction requires the involvement of several stakeholders [45]. Nevertheless, the procedures were found to logically follow the relevant decision making processes and to have adequate functionality and provide sufficient information for a team leader to proceed with anticipated actions.

Symbols that were developed for the purpose of visualizing task information, including maturity and status, were generally well accepted, apart from the contingency task information box. This is one of only a few that was not created with a standard set of symbols found elsewhere (e.g. traffic signs). The evaluation revealed that the interfaces for Activities 5, 6 and 8 usefully provide system access for team leaders. There were concerns whether it is practical to use touch screens on construction sites due to adverse conditions, which confirms earlier studies on the use of IT equipment in construction $[1,46]$. Recent developments in all-weather sunlight readable touch screens promise a 
much better use in construction, but security from theft and vandalism remains a challenge. Practitioners also agreed that there are often so called 'make-do' situations where tasks should be allowed to start even if they are not mature. The responses clearly indicate that team leaders should be allowed to independently judge such situations, but that the system should in turn support the decision making with appropriate and sufficiently detailed information. Although make-do behavior has been found to be detrimental to the success of projects there is evidence in the literature that construction processes should be sufficiently flexible to allow for early start of somewhat immature tasks with some unavailable inputs [47]. Without exception, all participants agreed that involving trade managers in the detailed planning process early on is crucial. This indicates the importance of project team integration for successful detailed planning that has been also supported by earlier studies [35].

The first round of evaluation led to several minor amendments of the proposed system requiring further evaluation that was performed during the second and third workshops. An equivalent fourstage approach with a single questionnaire divided into four sections was used in this second round (see Table 2). Considering similarities in the user interface formats and time restrictions this second evaluation only covered the interfaces for activities 5,6 and 8 , but the questionnaire contained an additional section on current conditions. The additional section was then used to correlate the issues identified by the participants with those the system is designed to eliminate.

The second workshop was held in the business school facility at the headquarters of a major construction management organization. There were 10 attendees, six from the construction management team of a 26 story office building under construction in London (planner, close-out manager, construction Manager, assistant construction Manager, senior construction manager and a director) and three from different subcontractors at the same project (two M\&E trade construction managers and a crew leader). The third workshop was held at the headquarters of a major BIM vendor in Espoo, Finland, with five participants (a senior construction manager, two 
subcontractor trade managers, and two BIM software designers). The criteria for contrasting the proposed principles and solutions against existing production management problems and a summary of the feedback obtained are presented in Table 4.

Table 4. Summary of evaluation criteria and feedback from the second and third workshops.

\begin{tabular}{|c|c|c|}
\hline Topic Evaluated & Evaluation criteria & Feedback Summary \\
\hline Section A: Current & Main reasons scheduled tasks are not completed on time & Preceding activities not completed on time, \\
\hline Conditions - & Main reason scheduled activities are not completed within & Workspace not ready for the start of next activity, \\
\hline \multirow[t]{4}{*}{ scheduled tasks } & allocated budget. & Preceding activities not completed with adequate \\
\hline & & $\begin{array}{l}\text { quality and Information not Ready or Available } \\
\text { are the main reasons. }\end{array}$ \\
\hline & How many scheduled tasks are either severely over time & Mixed results with no clear indication of how \\
\hline & or over budget? & $\begin{array}{l}\text { many activities are severely over budget or over } \\
\text { time. }\end{array}$ \\
\hline Section B: & Importance of following the plan. & Following the plan regardless of well known \\
\hline Proposed principles & Early involvement of trade contractors in weekly planning. & issues and problems is extremely important. \\
\hline \multirow[t]{6}{*}{ - planning } & General contractor's motivation for following the plan. & Keeping to project schedule, Maximizing \\
\hline & Trade contractor's motivation for following the plan. & Productivity and Reducing the Amount of Work in \\
\hline & & $\begin{array}{l}\text { Progress are the main motivation for following } \\
\text { the plan for both main contractors and trade }\end{array}$ \\
\hline & Trade contractors' behavior (starting tasks and competing & contractors. \\
\hline & for spaces) & Trade contractors usually start tasks as soon as \\
\hline & & they can and often compete for available spaces. \\
\hline Section B: & Is visualization necessary to improve management of & Appropriate visualization is necessary due to \\
\hline Visualization and & tasks? & complexity of tasks and interdependencies. \\
\hline \multirow[t]{5}{*}{ indices } & Are Maturity and Pull Flow Indices useful indicators & They are very useful but it is unclear how they will \\
\hline & enabling selecting tasks that have higher chances of & be attained and whether they can be trusted. \\
\hline & smooth work and continuity? & \\
\hline & User interface restricts the user to select only mature & Trade managers should be allowed to judge each \\
\hline & tasks. & situation separately to minimize restrictions. \\
\hline Section C: Activity & Importance of the availability of product/process & Product/process information vital for team \\
\hline \multirow[t]{2}{*}{6,7 and 8 user } & information for team leaders. & leaders. \\
\hline & Effectiveness, practicality and usefulness of touch screens & They are useful but could be accompanied by \\
\hline
\end{tabular}


Requirements for Building Information Modeling based Lean Production Management Systems for Construction Accepted 2/2010 for Automation in Construction $\quad$ (C) 2010 Sacks, Radosavljevic, Barak

interfaces

Section D: General

Evaluation

\begin{abstract}
for gathering process information from team leaders.
Can team leaders be expected to navigate the BIM model?

Can team leaders be expected to select completed objects

within a task in a reliable way?

How important is the evaluation and reporting of the

maturity of the tasks for everyday work, reporting and

control?

Potential for waste minimization as a result of available

information through a control card.
\end{abstract}

How do touch screens compare against PDA, tablet PCs,

smart phones and wearable computers?

What major benefits would be achieved from using the

proposed BIM-based production system?

What changes would you suggest to improve the

proposed BIM-based production system? tablet PCs.

Despite its simplicity they would need training.

Yes but only after adequate training and testing.

It is vital to make the system reliable as this is the main problem of existing 3D-based systems.

There is potential for waste minimization because team leaders would obtain all relevant information from a single source.

Touch screens should be accompanied by tablet PCs but are better than PDAs or wearable PCs. Availability of relevant information when needed, elimination of fire-fighting, focusing on tasks and stability of work flow are the major benefits. No major changes were suggested apart from adequate training, addressing security and siteconditions issues, and making sure the system is updated to achieve reliability.

The second round highlighted several important factors that impact the production process in construction. 'Preceding activities not completed on time', 'workspaces not ready for the start of the next activity', 'preceding activities not completed with adequate quality', and 'information not ready or unavailable' were found to be the main factors.

There was an overwhelming consensus among participants in all workshops that trade subcontractors should participate in setting up weekly work plans. However, once set they should not be allowed to make any future changes without project/construction manager's approval, which points towards commitment and reliability as the main decision-making criteria in detailed planning. Keeping to schedule, maximizing productivity and reducing the amount of work in progress were for main contractors and sub-contractors the three most important motivators for setting weekly work 
plans. Most agreed that sub-contractors normally start their activities as soon as they can and also often compete for available workspace. Most therefore strongly agree that visualization on site using 3D building information models could improve management of often competing activities.

Participants agreed that the system could provide full project integration and link relevant information to a 3D model but also identified the following drawbacks and necessary conditions:

- Training (despite being simple to use many believe team leaders would require extensive training to get used to the new reality and avoid potential errors or misuse)

- Managing change (the existing use of 3D planning software shows that it is extremely difficult to promptly update models as a result of design and other changes)

- Site conditions (adversarial site conditions, weather and poor IT infrastructure are the major factors that could prevent successful implementation of the system)

\section{Conclusions}

A set of guiding requirements for implementation and operation of a BIM based lean production management system for construction has been compiled through development of the KanBIM concept. The requirements were derived through research in which a system was specified, prototype interfaces were implemented and tested using a touch-screen unit for site communications, and in which the approach was evaluated with construction companies. The key requirements concern issues of visualization of the construction process and its status; visualization of the construction product and work methods; support for planning, negotiation, commitment and status feedback; implementation of pull flow control; maintenance of work flow and plan stability; and formalizing production experiments for continuous process improvement. The requirements emphasize the role of a KanBIM system in supporting human decision making, negotiation among trade teams to coordinate weekly work plans, reduction of the granularity of planning to a daily 
level, real-time evaluation of task constraints to compute task maturity, and implementation of the language/action perspective.

The primary contribution of the KanBIM concept is that it provides visualization not only of the construction product, but of the production process. It extends the LPS by providing the information infrastructure to reduce the granularity of planning coordination from weekly to daily. It enables negotiation between parties affected by changes and informs - and thus empowers - all others on and off site of any changes agreed to the plan in real-time. As such, it can contribute to relieving the need for construction managers to 'fight fires' and enable them to focus on establishing the production systems, setting policy and continuous improvement. If used with the priority pull flow index, it will also extend the LPS's ability to stabilize plans by enabling implementation of a CONWIP production system.

The qualitative feedback resulting from the discussions and questionnaires used in the three workshops indicates that practitioners were generally supportive of the system and its aim to improve management in construction but they agreed that the system requires careful addressing of potential problems. According to the received feedback site conditions, security and human behavior are among the most serious problems that could affect the implementation of the system. Project team integration by means of sub-contractors' involvement in the detailed planning process and the need to better visualize production/process information were all found to be highly significant for the successful production management. However, adequate testing on site in order to establish to what extent technical difficulties can impact upon the usefulness of the system and behavioral investigation of its use have been identified as prerogative before the system could see the full scale application in the industry.

This paper has outlined the concept and defined the requirements and presented a system design for a BIM enabled lean production management system for construction. Evaluation to date has identified the value of the system concept, but also shortcomings in the interface designs. Clearly, 
further research is needed before a full scale KanBIM system can be built. Future work will include testing of the algorithms for calculation of work package and task maturity, development of the pull flow index and its computation, experimentation to explore the feasibility for guiding teams' progress through projects using the touch-screen or other interfaces, and the information technology challenges of maintaining an updated construction process model within a construction BIM tool.

\section{Acknowledgement}

The research reported in this paper was supported by grants from the Innovative Construction Research Centre at the University of Reading, UK, and from Tekla Oy, Espoo, Finland.

\section{References}

[1] L. Koskela, An exploration towards a production theory and its application to construction, D. Tech, VTT Building Technology, Helsinki University of Technology, 2000.

[2] I.D. Tommelein, D.R. Riley, G.A. Howell, Parade Game: Impact of Work Flow Variability on Trade Performance, Journal of Construction Engineering and Management 125 (5) (1999) 304-310.

[3] H.H. Bashford, K. Walsh, A. Sawhney, Production System Loading-Cycle Time Relationship in Residential Construction, J. Constr. Engrg. and Mgmt. 131 (1) (2005) 15-22.

[4] R. Sacks, A. Esquenazi, M. Goldin, LEAPCON: Simulation of Lean Construction of High-Rise Apartment Buildings, Journal of Construction Engineering and Management 133 (7) (2007) 529-539.

[5] G. Ballard, The Last Planner ${ }^{\mathrm{TM}}$ System of Production Control, PhD Dissertation, School of Civil Engineering, The University of Birmingham, 2000.

[6] L. Koskela, Management of Production in Construction: A Theoretical View, 7th Annual Conference of the International Group for Lean Construction, University of California, Berkeley, CA, 1999, pp. 241-252.

[7] R. Sacks, M. Harel, An economic game theory model of subcontractor resource allocation behavior, Construction Management \& Economics 24 (8) (2006) 869-881.

[8] M. Radosavljevic, R.M.W. Horner, The evidence of complex variability in construction labour productivity, Construction Management and Economics 20 (1) (2002) 3 - 12. 
[9] R. Navon, R. Sacks, Assessing research issues in Automated Project Performance Control (APPC), Automation in Construction 16 (4) (2007) 474-484.

[10] C.M. Eastman, P. Teicholz, R. Sacks, K. Liston, BIM Handbook: A Guide to Building Information Modeling for Owners, Managers, Architects, Engineers, Contractors, and Fabricators, John Wiley and Sons, Hoboken, NJ, 2008.

[11] J.E. Liker, The Toyota Way, McGraw-Hill, New York, 2003.

[12] G.G. Galsworth, Visual Systems: Harnessing the power of a visual workplace, 1st edition (January 15, 1997) ed., AMACOM/American Management Association, New York City, 1997.

[13] W.J. Hopp, M.L. Spearman, Factory Physics, IRWIN, Chicago, 1996.

[14] R. Arbulu, A. Koerckel, F. Espana, Linking production-level workflow with materials supply, in: R. Kenley (Ed.), 13th Conference of the International Group for Lean Construction, University of New South Wales, Sydney, Australia, 2005, pp. 199-206.

[15] K. McKinney, M. Fischer, Generating, evaluating and visualizing construction schedules with CAD tools, Automation in Construction 7 (6) (1998) 433-447.

[16] CommonPoint, Common Point Inc., Common Point Inc., Mountain View, CA, http://www.commonpointinc.com/, last accessed December 2007.

[17] Synchro, Synchro, Synchro Ltd, Coventry UK, www.synchroltd.com/, last accessed December 2007.

[18] B. Akinci, M. Fischer, J. Kunz, Automated Generation of Work Spaces Required by Construction Activities, Journal of Construction Engineering and Management 128 (4) (2002) 306-315.

[19] VICO, Virtual Construction 2007, Vico Software, Inc., Boulder, CO, http://www.vicosoftware.com/, last accessed April 2007.

[20] H.J. Choo, I.D. Tommelein, G. Ballard, T.R. Zabelle, WorkPlan: Constraint-Based Database for Work Package Scheduling, Journal of Construction Engineering and Management 125 (3) (1999) 151-160.

[21] A. Koerckel, G. Ballard, Return on investment in construction innovation - a lean construction case study, in: Russell (Ed.), 13th Annual Conference on Lean Construction, UNSW, Sydney, Australia, 2005.

[22] E. Sriprasert, N. Dawood, Multi-Constraint Information Management and Visualisation for Collaborative Planning and Control in Construction, ITcon - IT in Construction 8 (2003) 341 366. 
[23] Bentley, ConstructSim, Bentley Inc., Exton, PA, http://www.bentley.com/enUS/Products/ConstructSim/, last accessed November 25th 2009.

[24] I. Starkov, TOKMO, Tokmo Solutions, Inc., Reston, VA, http://tokmo.com/product.html, last accessed 16th December 2009.

[25] R. Sacks, M. Treckmann, O. Rozenfeld, Visualization of Work Flow to Support Lean Construction, Journal of Construction Engineering and Management 135 (12) (2009) 13071315.

[26] K.N. Hewage, J.Y. Ruwanpura, A novel solution for construction on-site communication - the information booth, Can. J. Civ. Eng. 36 (4) (2009) 659-671.

[27] L. Koskela, G. Howell, The Underlying Theory of Project Management Is Obsolete, Engineering Management Review, IEEE 36 (2) (2008) 22-34.

[28] N. Costantino, R. Pietroforte, Subcontracting practices in USA homebuilding: an empirical verification of Eccles's findings 20 years later, European Journal of Purchasing \& Supply Management 8 (2002) 15-23.

[29] S. Kubicki, J.C. Bignon, G. Halin, P. Humbert, Assistance to building construction coordination - towards a multi-view cooperative platform, ITcon - IT in Construction 11 (Special Issue Process Modelling, Process Management and Collaboration) (2006) 565-586.

[30] A.D. Songer, P.S. Subramanian, J.E. Diekmann, Integrating workflow modeling and 3d cad for visualizing project performance, CIB W78, Reykjavik, Iceland, 2000.

[31] R. Navon, E. Goldschmidt, Can Labor Inputs be Measured and Controlled Automatically?, ASCE Journal of Construction Engineering and Management 129 (4) (2003) 437-445.

[32] R. Sacks, R. Navon, I. Brodetskaia, A. Shapira, Feasibility of Automated Monitoring of Lifting Equipment in Support of Construction Project Control, ASCE Journal of Construction Engineering and Management 131 (5) (2005) 604-614.

[33] F. Bosche, C.T. Haas, Towards Automated Retrieval of 3D Designed Data in 3D Sensed Data, in: S. Lucio, A. Burcu (Eds.), ASCE International Workshop on Computing in Civil Engineering Vol. 261, ASCE, Pittsburgh, PA, 2007, pp. 648-656.

[34] T. Sawyer, \$1-Billion Jigsaw Puzzle Has Builder Modeling Supply Chains, Engineering News Record, Vol. 23rd April 2008, 2008.

[35] M. Radosavljevic, R.M.W. Horner, Process planning methodology: dynamic short-term planning for off-site construction in Slovenia, Construction Management and Economics 25 (2) (2007) 143-156. 
[36] R.C. Bortolazza, D.B. Costa, C.T. Formoso, A quantitative analysis of the implementation of the Last Planner System in Brazil, in: R. Kenley (Ed.), 13th Conference of the International Group for Lean Construction, UNSW, Sydney, Australia, 2005, pp. 413-420.

[37] A.D. Russell, C.-Y. Chiu, T. Korde, Visual representation of construction management data, Automation in Construction 18 (8) (2009) 1045-1062.

[38] K. Chau, M. Anson, Z. J., 4D dynamic construction management and visualization software, Automation in Construction 14 (2005) 512-524.

[39] R.R. Lipman, Mobile 3D visualization for steel structures, Automation in Construction 13 (1) (2004) 119-125.

[40] K. Preiss, Agility and Leanness, Proceedings of the International Conference on Agile Manufacturing, Old Dominion University, Norfolk, VA, 2006.

[41] T. Winograd, A Language/Action Perspective on the Design of Cooperative Work, HumanComputer Interaction 3 (1) (1987) 3 - 30.

[42] R. Vrijhoef, L. Koskela, G. Howell, Understanding construction supply chains: an alternative interpretation, in: D. Chua, G. Ballard (Eds.), Proceedings of the 9th Annual Conference of the International Group for Lean Construction (IGLC), National University of Singapore, Singapore, 2001.

[43] R. Partouche, A Lean Model for Construction Management of Tall Office/Commercial Buildings, MSc, Faculty of Civil and Env. Eng., Technion - Israel Institute of Technology, 2009.

[44] W.E. Deming, Out of the Crisis, Massachusetts Institute of Technology, Cambridge, MA, 1982.

[45] B.K. Baiden, A.D.F. Price, A.R.J. Dainty, The Extent of Team Integration within Construction Projects, International Journal of Project Management 24 (1) (2006) 13-23.

[46] T. Olofsson, M. Emborg, Feasibility Study of Field Force Automation in the Swedish Construction Sector, ITcon 9 (2004) 297-311.

[47] L. Koskela, Making Do - The Eighth Category of Waste, in: C.T. Formoso, S. Bertelsen (Eds.), 12th Annual Conference on Lean Construction, Lean Construction - DK, Elsinore, Denmark, 2004. 
Requirements for Building Information Modeling based Lean Production Management Systems for Construction Accepted 2/2010 for Automation in Construction

(C) 2010 Sacks, Radosavljevic, Barak

\section{List of Tables}

Table 1. Supplier reliability $R_{k}$ based on its record of project performance to date.

Table 2. Aspects of construction planning and control according to level of planning.

Table 3. Summary of evaluation criteria and feedback from the first workshop.

Table 4. Summary of evaluation criteria and feedback from the second and third workshops.

\section{$\underline{\text { List of Figures }}$}

Fig. 1. Proposed 3D visualization of past, present and future work status for a trade [25].

Fig. 2. Visualization of drywall tasks color-coded to identify process status, as used by a Finnish construction management company.

Fig. 3. Process flow model for the KanBIM system.

Fig. 4. User interface for detailing work packages to tasks and compiling the weekly work plan by allocating crews to tasks

Fig. 5. Weekly work plan meeting setup

Fig. 6. Project planner contractor view interface for creating integrated and synchronized weekly work plans.

Fig. 7. Trade crew leader work status and reporting interface showing a crew's tasks. The crew leader can ask the system to show neighboring tasks for a complete picture of the overall work.

Fig. 8. Reporting start of a drywall activity on a building model interface using a 40" all-weather touch-screen monitor mounted on a mobile trolley. The system identifies trade crew leaders (by RFID tag or by entry of a unique ID) and delivers specifically tailored information concerning their tasks' status and content.;

Fig. 9. Reporting form for problems during execution which led to stopping the task. The reporting tool enables information flow from the work face back to the information servers to create an up-todate image of the work status and to raise flags when problems are encountered.

Fig. 10. Control card for framing drywall partition task 